\title{
Live Rats Resulting From Injection of Oocytes With Spermatozoa Freeze-Dried and Stored for One Year
}

\author{
SHINICHI HOCHI, ${ }^{1 *}$ KAORI WATANABE, ${ }^{1}$ MEGUMI KATO,${ }^{2}$ AND MASUMI HIRABAYASHI ${ }^{2,3 * *}$ \\ ${ }^{1}$ Faculty of Textile Science and Technology, Shinshu University, Ueda, Nagano, Japan \\ ${ }^{2}$ National Institute for Physiological Sciences, Okazaki, Aichi, Japan \\ ${ }^{3}$ The Graduate University of Advanced Studies, Okazaki, Aichi, Japan
}

\begin{abstract}
This study was designed to examine whether rat spermatozoa after freeze-drying and 1 -year storage can participate in full-term development following intracytoplasmic sperm injection (ICSI). Cauda epididymal spermatozoa from Crlj:Wistar rats were frozen in liquid nitrogen $\left(\mathrm{LN}_{2}\right)$, first dried for $14 \mathrm{hr}$ at $0.37 \mathrm{hPa}$ and then for $3 \mathrm{hr}$ at $0.001 \mathrm{hPa}$. The dried spermatozoa were stored for 1 year in a desiccator at $+25^{\circ} \mathrm{C}$, or in a refrigerator at $+4^{\circ} \mathrm{C}$, or in $\mathrm{LN}_{2}$ at $-196^{\circ} \mathrm{C}$. Controls consisted of sperm that had only been frozen and stored in $\mathrm{LN}_{2}$. After being stored, spermatozoa were sonicated to dissociate the sperm tail and were injected into oocytes from superovulated Slc:SD rats. The respective fertilization rates of oocytes injected with frozen sperm, or with freeze-dried sperm stored at $+25,+4$, and $-196^{\circ} \mathrm{C}$ were $79 \%, 75 \%$, $70 \%$, and $73 \%$. However, the corresponding cleavage rates of injected oocytes were $63 \%, 1 \%, 38 \%$, and $36 \%$. After transfer of $>80$ zygotes of each group into recipients, the respective percentages of full-term normal offspring resulting from frozen sperm or from freeze-dried sperm stored at $+25,+4$, and $-196^{\circ} \mathrm{C}$ were $36 \%, 0 \%, 7 \%$, and $14 \%$. These results demonstrate that the storage temperature significantly influenced the likelihood of term development of rats produced by injection of oocytes with freezedried spermatozoa. Chromosomal analysis of the rat spermatozoa in the ICSI oocytes indicated that chromosomal aberration in freeze-dried spermatozoa stored at $+25^{\circ} \mathrm{C}(100 \%)$ occurred more frequently than in frozen control spermatozoa (41\%) and freezedried spermatozoa stored at $-196^{\circ} \mathrm{C}(35 \%)$, and the frequency of chromosomal aberrations in freezedried spermatozoa stored at $+4^{\circ} \mathrm{C}(65 \%)$ was the intermediate. In conclusion, rat spermatozoa freezedried and stored at $+4^{\circ} \mathrm{C}$ for 1 year are capable of participating in full-term development after ICSI. Mol. Reprod. Dev. 75: 890-894, 2008.

(C) 2007 Wiley-Liss, Inc.
\end{abstract}

Key Words: chromosome; freeze-dry; ICSI; storage; rat spermatozoa

\section{INTRODUCTION}

If freeze-dried spermatozoa can be preserved for extended times at ambient or refrigeration temperatures, the cost for maintenance and shipping of spermatozoa would be reduced because neither dry ice nor liquid nitrogen $\left(\mathrm{LN}_{2}\right)$ would be required. Offspring derived from intracytoplasmic injection of freeze-dried spermatozoa were first reported in mouse (Wakayama and Yanagimachi, 1998), and then followed in rabbit (Liu et al., 2004) and rat (Hirabayashi et al., 2005). But a practical method to store freeze-dried spermatozoa for extended times has been documented only for the mouse (Kaneko et al., 2003; Ward et al., 2003; Kaneko and Nakagata, 2005; Kawase et al., 2005a). Mouse spermatozoa can be stored after freeze-drying for up to 1.5 years without remarkable reduction in the contribution to development into fullterm offspring (Ward et al., 2003; Kaneko and Nakagata, 2005). In contrast, the first rat offspring derived from freeze-dried spermatozoa were produced by intracytoplasmic sperm injection (ICSI) after 2-days storage at $+4 \mathrm{C}$ in our laboratory (Hirabayashi et al., 2005). A first rabbit young derived from freeze-dried spermatozoon was produced by transfer of 230 ICSI oocytes after 2 years storage of the freeze-dried spermatozoa (Liu et al., 2004). Except for Kawase et al. (2005a, 2007) who successfully applied a programmable freeze-dryer for mouse spermatozoa, the freeze-drying process for spermatozoa has been achieved under a single vacuum pressure $(<0.05 \mathrm{hPa})$.

Therefore in the present study, we aimed to produce rat offspring after a longer storage period of spermatozoa freeze-dried in a programmable freezedryer. Post-implantation developmental potential of ICSI oocytes and chromosomal integrity using freezedried rat spermatozoa stored for 1 year at three different

Grant sponsor: Ministry of Education, Culture, Sports, Science and Technology of Japan; Grant number: 15082211; Grant sponsor: Japan Society for the Promotion of Science; Grant numbers: 17658124, 19300150.

*Correspondence to: Shinichi Hochi, Laboratory of Reproductive Biology, Faculty of Textile Science and Technology, Shinshu University, Ueda, Nagano 386-8567, Japan. E-mail: shochi@shinshu-u.ac.jp **Correspondence to: Masumi Hirabayashi, Section of Mammalian Transgenesis, Center for Genetic Analysis of Behavior, National Institute for Physiological Sciences, Okazaki, Aichi 444-8787, Japan. E-mail: mhirarin@nips.ac.jp

Received 29 May 2007; Accepted 13 July 2007

Published online 9 October 2007 in Wiley InterScience

(www.interscience.wiley.com).

DOI 10.1002/mrd.20825 
temperatures $\left(+25,+4\right.$, and $\left.-196^{\circ} \mathrm{C}\right)$ as well as control spermatozoa frozen and stored in liquid nitrogen were investigated.

\section{MATERIALS AND METHODS}

\section{Freeze-Drying and Storage of Rat Spermatozoa}

Our animal experimentation was reviewed and approved by Animal Care and Use Committees of the Shinshu University and the National Institute for Physiological Sciences, and all procedures for handling and treatment of the animals were conducted according to the Guidelines of the Committees. Cauda epididymal spermatozoa from three different Crlj:Wistar male rats ( $\geq 12$ weeks old; Charles River Japan, Kanagawa, Japan) were suspended in a solution consisting of $10 \mathrm{mM}$ Tris- $\mathrm{HCl}, 50 \mathrm{mM}$ EGTA and $50 \mathrm{mM} \mathrm{NaCl}$ (pH 8.0) to yield a final concentration of $5-10 \times 10^{6}$ cells $/ \mathrm{ml}$. The $500-\mu \mathrm{l}$ aliquots were placed into 5 -ml volume glass vials (no. 2; Maruemu, Osaka, Japan), and then frozen by plunged into $\mathrm{LN}_{2}$ of 1-cm depth. The frozen samples were transferred onto the shelf $\left(-30^{\circ} \mathrm{C}\right)$ of a programmable freeze-dryer (ALPHA 2-4; Christ, Harz, Germany), and dried primary for $14 \mathrm{hr}$ at $0.37 \mathrm{hPa}$ and secondary for $3 \mathrm{hr}$ at $0.001 \mathrm{hPa}$. During the process of primary drying, the shelf temperature was controlled to increase to $+30^{\circ} \mathrm{C}$. After fulfilling with inactive $\mathrm{N}_{2}$ gas and sealing the vials with rubber caps and parafilm, the dried samples were transferred in a conventional glass desiccator (5-L volume) at $+25 \pm 5^{\circ} \mathrm{C}$, in a refrigerator (300-L volume) at $+4^{\circ} \mathrm{C}$, or in a $\mathrm{LN}_{2}$ tank (30-L volume) at $-196^{\circ} \mathrm{C}$, and then stored for 1 year under dark conditions.

In each experiment, a few vials with sperm cells suspended in the above solution $(500-\mu \mathrm{l}$ of $10 \mathrm{mM}$ Tris$\mathrm{HCl}, 50 \mathrm{mM}$ EGTA and $50 \mathrm{mM} \mathrm{NaCl}$ ) were randomly selected, and sealed with rubber caps and parafilm. They were frozen in $\mathrm{LN}_{2}$ as described above, and then stored for 1 year in $\mathrm{LN}_{2}$ at $-196^{\circ} \mathrm{C}$. These non-dried samples were used as controls.

\section{Ooplasmic Injection of Rehydrated Spermatozoa}

Ooplasmic injection was performed according to the method described previously (Hirabayashi et al., 2002, 2005). Briefly, Slc:SD female rats (Sprague-Dawley, 57 weeks old; Japan SLC, Shizuoka, Japan) were superovulated with intraperitoneal injections of $300 \mathrm{IU} / \mathrm{kg}$ equine chorionic gonadotropin (eCG; Serotrophin, Aska Pharmaceutical Co., Tokyo, Japan) and 300 IU/kg human chorionic gonadotropin (hCG; Gonatrophin, Aska) at an interval of $48 \mathrm{hr}$. Fifteen to $17 \mathrm{hr}$ after the hCG injection, cumulus-oocyte complexes were recovered with mR1ECM supplemented with $0.4 \%$ BSA (mR1ECM/BSA; Oh et al., 1998). Oocytes were freed from cumulus cells by a 5 min-treatment with $0.1 \%$ hyaluronidase (Sigma Chemicals Co., St. Louis, MO). The freeze-dried spermatozoa were rehydrated by adding $500-\mu$ l of ultrapure milli-Q water to the vial, and then sonicated for 10 sec using a $10 \%$ power output from an ultrasonic cell disrupter (Sonifier
250; Branson, Danbury, CT). The sperm heads were injected into the denuded oocytes using a piezo-driven micromanipulator (PMM-150FU; Prime Tech, Ibaraki, Japan) in the mR1ECM medium modified by the addition of Hepes at $22 \mathrm{mM}$ and the reduction of sodium bicarbonate to $5 \mathrm{mM}$. The Hepes-buffered mR1ECM medium supplemented with $12 \%$ polyvinylpyrrolidone (PVP; Sigma) was used for placing the sperm heads immediately before their injection in order to facilitate the sperm handling.

\section{In Vitro Culture and Embryo Transfer}

Oocytes following ICSI were washed three times with mR1ECM/BSA and cultured in 100- $\mu \mathrm{l}$ microdrops of the same medium covered with mineral oil at $37^{\circ} \mathrm{C}$ in $5 \% \mathrm{CO}_{2}$ in air. The morphological survival rates and cleavage rates were assessed at 6 and $24 \mathrm{hr}$ later, respectively, after completing the ICSI. Presumptive zygotes at the 2-cell stage and non-degenerating 1-cell stage were harvested $24 \mathrm{hr}$ after ICSI, and then transferred into the oviductal ampullae of the recipient rats (Crlj:Wistar, $\geq 10$ weeks old) which had been previously mated with a vasectomized male rat. Embryo transfer to the pseudopregnant recipients (19-29 embryos per recipient) was performed on the day that a vaginal plug was detected. Three weeks later, pregnant recipients were delivered by Caesarean section. The numbers of implantation sites (including those with viable offspring) and full-term offspring were recorded.

\section{Chromosomal Analysis}

Chromosomal integrity of rat spermatozoa was analyzed in rat oocytes according to the method reported in mouse oocytes (Kamiguchi and Mikamo, 1986). All the sperm samples after rehydration for ICSI experiments were re-frozen and stored in $\mathrm{LN}_{2}$ for a few months until the analysis. Sperm heads were injected into the SD rat oocytes as described above, and $6 \mathrm{hr}$ later the ICSI oocytes with two distinct pronuclei and second polar body were placed for $14 \mathrm{hr}$ in the mR1ECM/BSA containing $6 \mathrm{ng} / \mathrm{ml}$ of vinblastin (Sigma) to arrest them at metaphase of the first cleavage. The oocytes were then removed from the zonae pellucidae with $0.5 \%$ pronase, and processed for the preparation of chromosome spreads on a glass slide. After Giemsa staining, two haploid sets of rat chromosomes in each preparation were evaluated as "normal" (an oocyte with two sets of 21 normal chromosomes), "minor aberrant" (an oocyte with 1-9 chromosomal breaks; Fig. 1A) or "severe aberrant" (an oocyte with more than 10 chromosomal breaks; Fig. 1B), as classified by Kaneko and Nakagata (2005).

\section{Statistics}

Three ICSI replicates using three different male rats were performed for each group. The developmental potential and chromosomal data were analyzed by Fisher's exact probability test. A value of $P<0.05$ was chosen as an indication of statistical significance. 


\section{Molecular Reproduction and Development}

A

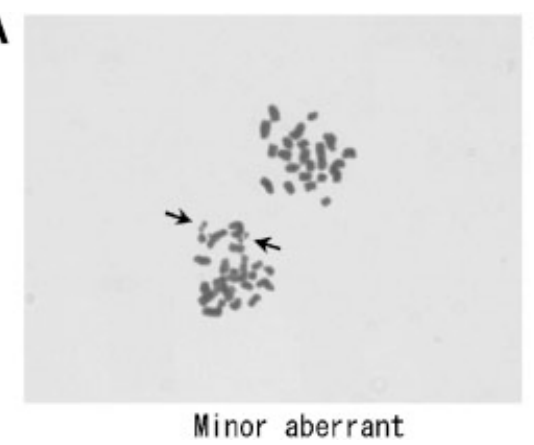

B

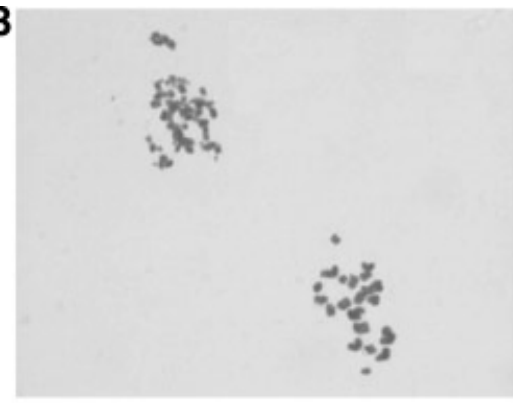

Severe aberrant

Fig. 1. Chromosomal aberrations observed in rat oocytes injected with freeze-dried sperm heads. Left panel, A: Minor aberrant karyoplate. Two chromosomal fragments were detected, as shown by arrows. Right panel, B: Severe aberrant karyoplate. Upper haploid set had multiple chromosomal breaks while the bottom maternal set appeared normal.

\section{RESULTS}

Developmental potential of SD rat oocytes after microinsemination with frozen or freeze-dried Wistar rat spermatozoa is shown in Table 1. Proportions of oocytes survived the ICSI were comparable among the four groups (84-89\%). The respective fertilization rates of oocytes injected with frozen sperm, or with freeze-dried sperm stored at $+25,+4$, and $-196^{\circ} \mathrm{C}$ were $79 \%, 75 \%, 70 \%$, and $73 \%$. However, the corresponding cleavage rates of injected oocytes were $63 \%, 1 \%, 38 \%$, and $36 \%$. After transfer of $>80$ zygotes of each group into recipients, the respective percentages of full-term normal offspring resulting from frozen sperm or from freeze-dried sperm stored at $+25,+4$, and $-196^{\circ} \mathrm{C}$ were $36 \%, 0 \%, 7 \%$, and $14 \%$. No significant difference in the offspring rate was found between the groups for freezedried spermatozoa stored at +4 and $-196^{\circ} \mathrm{C}$. Failure of implanted embryos to develop into full-term (embryonic loss during the mid-gestation period) occurred more frequently in freeze-dried groups than frozen control group. All offspring retrieved by Caesarean section were viable and appeared to be normal.

Based on the number of oocytes that exhibited both pronuclei and a second polar body after ICSI, the success rates for preparing chromosomal spreads were $47 \%$ (37/ $78), 64 \%(34 / 53), 52 \%(40 / 77)$, and $41 \%(36 / 88)$ in the groups for frozen control spermatozoa, freeze-dried spermatozoa stored at $-196,+4$, and $+25^{\circ} \mathrm{C}$, respectively. Chromosomal integrity of frozen or freeze-dried rat spermatozoa was summarized in Figure 2. Chromosomal aberration in freeze-dried spermatozoa stored at $+25^{\circ} \mathrm{C}(100 \%)$ occurred more frequently than in frozen control spermatozoa (41\%) and freeze-dried spermatozoa stored at $-196^{\circ} \mathrm{C}(35 \%)$, and the aberrant frequency in freeze-dried spermatozoa stored at $+4^{\circ} \mathrm{C}(65 \%)$ was the intermediate. Severe aberrations $(\geq 10$ chromosomal breaks) were detected in all the oocytes injected with freeze-dried spermatozoa stored at $+25^{\circ} \mathrm{C}$, while abnormalities of sperm chromosomes in the other groups were minor. Mean numbers of chromosomal breaks in the minor aberrant karyoplates of oocytes injected with spermatozoa frozen and stored at $-196^{\circ} \mathrm{C}$ $(2.8 \pm 1.2)$, freeze-dried and stored at $-196^{\circ} \mathrm{C}(1.4 \pm 0.9)$, and freeze-dried and stored at $+4^{\circ} \mathrm{C}(2.5 \pm 1.6)$ were comparable.

\section{DISCUSSION}

In the mouse, the stability of freeze-dried spermatozoa has been drastically improved (Kusakabe et al., 2001; Kaneko et al., 2003; Ward et al., 2003; Kaneko and Nakagata, 2005, 2006; Kawase et al., 2005a,b, 2007), whereas it is still questionable in other species. The

TABLE 1. In Vitro and In Vivo Development of Rat Oocytes Microinseminated With Freeze-Dried Spermatozoa After Long-Term Storage

\begin{tabular}{|c|c|c|c|c|c|c|c|c|}
\hline \multirow[b]{2}{*}{$\begin{array}{l}\text { Sperm } \\
\text { treatments }\end{array}$} & \multirow[b]{2}{*}{$\begin{array}{c}\text { Storage } \\
\text { temperatures }\left({ }^{\circ} \mathrm{C}\right)\end{array}$} & \multicolumn{4}{|c|}{ No. (\%) of oocytes } & \multicolumn{3}{|c|}{ No. $(\%)$ of zygotes } \\
\hline & & Injected & Surviving & $\begin{array}{l}\text { Fertilized } \\
(2 \mathrm{PN}+\mathrm{pb})^{\mathrm{a}}\end{array}$ & Cleaved $^{\mathrm{a}}$ & Transferred & Implanted $^{\mathrm{a}}$ & $\begin{array}{l}\text { Developed } \\
\text { to offspring }\end{array}$ \\
\hline Frozen & -196 & 104 & $90(87)^{\mathrm{a}}$ & $71(79)^{\mathrm{a}}$ & $57(63)^{\mathrm{a}}$ & 84 & $63(75)^{\mathrm{a}}$ & $30(36)^{\mathrm{a}}$ \\
\hline Freeze-dried & -196 & 125 & $107(86)^{\mathrm{a}}$ & $78(73)^{\mathrm{a}}$ & $38(36)^{\mathrm{b}}$ & 90 & $48(53)^{\mathrm{b}}$ & $13(14)^{\mathrm{b}}$ \\
\hline Freeze-dried & +4 & 128 & $114(89)^{\mathrm{a}}$ & $80(70)^{a}$ & $43(38)^{\mathrm{b}}$ & 102 & $36(35)^{\mathrm{c}}$ & $7(7)^{\mathrm{b}}$ \\
\hline Freeze-dried & +25 & 114 & $96(84)^{\mathrm{a}}$ & $72(75)^{\mathrm{a}}$ & $1(1)^{\mathrm{c}}$ & 87 & $4(5)^{\mathrm{d}}$ & $0(0)^{\mathrm{c}}$ \\
\hline
\end{tabular}

Values with different superscripts within each column are significantly different $(P<0.05)$.

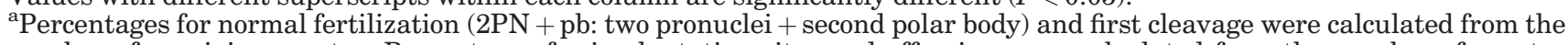
number of surviving oocytes. Percentages for implantation sites and offspring were calculated from the number of zygotes transferred. 


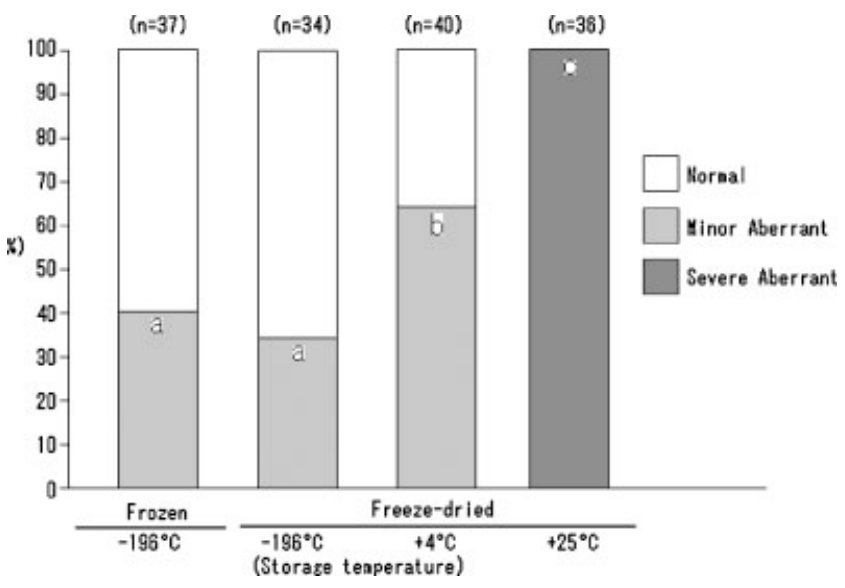

Fig. 2. Chromosomal analysis of rat spermatozoa freeze-dried and stored for 1 year at three different temperatures. Spermatozoa frozen and stored for 1 year at $-196^{\circ} \mathrm{C}$ were served as controls. Numbers in parentheses on columns indicate the number of chromosomal preparations evaluated. Different letters (a vs. b vs. c) denote significant difference in incidence of chromosomal aberrations $(P<0.05)$

present result indicated that rat spermatozoa after freeze-drying and 1-year preservation at $+4{ }^{\circ} \mathrm{C}$ were capable of participating into full-term development (Table 1). Our previous freeze-drying protocol for rat spermatozoa $(0.1 \mathrm{hPa}, 6 \mathrm{hr}$; Hirabayashi et al., 2005) failed to produce offspring using freeze-dried rat spermatozoa preserved for 6 weeks at $+4^{\circ} \mathrm{C}$ (unpublished data). Although the follow-up study of this failure was insufficient, a programmable freezedryer, by which sperm samples can be dried under different vacuum pressures in a stepwise manner, was used in the present study. The vacuum pressures during primary drying $(0.37 \mathrm{hPa})$ and secondary drying $(0.001 \mathrm{hPa})$ were determined according to the values for freeze-drying of mouse spermatozoa presented by Kawase et al. (2005b). The importance of primary vacuum pressure during freeze-drying of mouse spermatozoa has been described very recently by Kawase et al. (2007). As to the reason why the primary step is effective for long-term stability of freeze-dried spermatozoa, a slower rate of dehydration from spermatozoa may be required for maintaining the cellular components without loss of function.

There was a considerable reduction in offspring rate when the freeze-dried rat spermatozoa were subjected to ICSI (Table 1). The in vivo result of present study may be preliminary because it is unclear how such a reduction is caused by suboptimal condition during freeze-drying process and/or the subsequent preservation. It is also unclear how the instability of freeze-dried rat spermatozoa is dependent on the preservation period. Further investigations on these interactions, as well as from a practical view such as dry container type (glass vial was used in this study) and rat strain difference $\left(\mathrm{SD} \times \mathrm{Wistar} \mathrm{F}_{1}\right.$ zygotes were produced in this study), are required. Concentration of chelating agent (Kaneko and Nakagata, 2006) and $\mathrm{pH}$ value (Kaneko et al., 2003) in freeze-drying solution are also among factors influencing stability of freeze-dried mouse spermatozoa. In the present study, the $\mathrm{pH}$ value was adjusted to be 8.0 as reported by Kusakabe et al. (2001) and Kaneko et al. (2003), while optimal composition of freeze-drying solution for rat spermatozoa also remains to be investigated.

Kaneko and Nakagata (2005) reported that chromosomal damage and full-term development of mouse oocytes microinjected with freeze-dried and long-term preserved spermatozoa were affected by the storage at $+24^{\circ} \mathrm{C}$ but not at $-70,-20$, and $+4^{\circ} \mathrm{C}$. Higher frequency of chromosomal damage in freeze-dried spermatozoa preserved at $+25^{\circ} \mathrm{C}$ versus $+4^{\circ} \mathrm{C}$ and $-196^{\circ} \mathrm{C}$ in the present study (Fig. 2) matched well with results of the above study (Kaneko and Nakagata, 2005). It is well known in mice that the ICSI procedure itself does not damage sperm chromosomes (Szczygiel et al., 2002). No significant difference between the frozen/thawed spermatozoa and freeze-dried/rehydrated spermatozoa $\left(-196^{\circ} \mathrm{C}\right.$ storage group) in their ability to maintain sperm chromosome integrity (Fig. 2) was also reported in rabbit (Liu et al., 2004) regardless of significant reduction in full-term developmental potential of oocytes injected with freeze-dried spermatozoa. In mice, the process of freeze-drying induced chromosomal aberrations to some extent (Kusakabe et al., 2001; Ward et al., 2003; Kaneko and Nakagata, 2006). No chromosomal aberrations were observed in SD rat oocytes injected with fresh spermatozoa from which tails were removed by a piezo pulse, while chromosomal aberrations occurred in approximately one-fourth of oocytes injected with frozen/piezo-treated or fresh/sonicated sperm heads (unpublished data). Therefore, the relatively high proportion of chromosomal aberrations in rat oocytes injected with frozen-thawed control spermatozoa (41\%, Fig. 2) was probably due to the ultrasonic treatment and/ or the freeze-thawing protocol employed.

In mice, ultrasonic treatment per se had no harmful effect on chromosomal integrity of spermatozoa (Tateno et al., 2000). We have reported that the ultrasonic treatment of rat spermatozoa contributed to improve full-term developmental potential of ICSI oocytes (Hirabayashi et al., 2005). Damage of DNA in mouse spermatozoa freeze-dried by a two-step manner (primary drying at $0.04 \mathrm{hPa}+$ secondary drying at $0.001 \mathrm{hPa}$ ) was reported with a comet assay (Kawase et al., 2005a), but no comet tails were detected in mouse spermatozoa freeze-dried at $0.37 \mathrm{hPa}+0.001 \mathrm{hPa}$ and stored for 6 months at $+4^{\circ} \mathrm{C}$ (Kawase et al., 2007). The result of chromosomal analysis using freeze-dried rat spermatozoa (Fig. 2) was not always coincident with the developmental potential of ICSI oocytes in vitro and in vivo (Table 1). Comparison of normal fertilization rate with the subsequent first cleavage rate (Table 1) suggests that function of freeze-dried rat spermatozoa for normal chromosomal distribution was damaged during long-term storage at room temperature, regardless of the fact that centrosome and microtubule 


\section{Molecular Reproduction and Development}

894

\section{S. HOCHI ET AL.}

organization for the first cleavage is dependent on maternal origin in small rodents including rats (Woolley and Fawcett, 1973; Schatten et al., 1986). Activation stimuli from the sperm heads for oocyte activation (sperm factor; a promising candidate is phospholipase

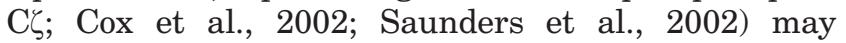
be qualitatively and/or quantitatively reduced during freeze-drying and subsequent storage. If so, a control of oocyte activation with chemicals will be beneficial.

In conclusion, rat spermatozoa are capable of participating into full-term development after freeze-drying and long-term storage at a refrigerator temperature. Further research is necessary to minimize DNA damage in freeze-dried/stored rat spermatozoa and to improve developmental potential of oocytes microinseminated with the rehydrated spermatozoa.

\section{ACKNOWLEDGMENTS}

We wish to thank Ms. K. Amemiya for technical assistance and Dr. Y. Fukazawa for use of a highresolution microscope. This study was supported in part by Grant-in-Aids from the Ministry of Education, Culture, Sports, Science and Technology of Japan (No. 15082211) and the Japan Society for the Promotion of Science (Nos. 17658124 and 19300150).

\section{REFERENCES}

Cox LJ, Larman MG, Saunders CM, Hashimoto K, Swann K, Lai FA. 2002. Sperm phospholipase $\mathrm{C} \zeta$ from humans and cynomolgus monkeys triggers $\mathrm{Ca}$ oscillations, activation and development of mouse oocytes. Reproduction 124:611-623.

Hirabayashi M, Kato M, Aoto T, Sekimoto A, Ueda M, Miyoshi I, Kasai N, Hochi S. 2002. Offspring derived from intracytoplasmic injection of transgenic rat sperm. Transgenic Res 11:221-228.

Hirabayashi M, Kato M, Ito J, Hochi S. 2005. Viable rat offspring derived from oocytes intracytoplasmically injected with freeze-dried sperm heads. Zygote 13:79-85.

Kamiguchi Y, Mikamo K. 1986. An improved, efficient method for analyzing human sperm chromosomes using zona-free hamster ova. Am J Hum Genet 38:724-740.

Kaneko T, Nakagata N. 2005. Relation between storage temperature and fertilizing ability of freeze-dried mouse spermatozoa. Comp Med 55:140-144.
Kaneko T, Nakagata N. 2006. Improvement in the long-term stability of freeze-dried mouse spermatozoa by adding of a chelating agent. Cryobiology 53:279-282.

Kaneko T, Whittingham DG, Yanagimachi R. 2003. Effect of $\mathrm{pH}$ value of freeze-drying solution on the chromosome integrity and developmental ability of mouse spermatozoa. Biol Reprod 68:136139.

Kawase Y, Araya H, Kamada N, Jishage K, Suzuki H. 2005a. Possibility of long-term preservation of freeze-dried mouse spermatozoa. Biol Reprod 72:568-573.

Kawase Y, Hani T, Kamada N, Jishage K, Suzuki H. 2005b. Improvement of the freeze-drying method for mouse spermatozoa. J Mamm Ova Res 22:S56 (abstract)

Kawase Y, Hani T, Kamada N, Jishage K, Suzuki H. 2007. Effect of pressure at primary drying of freeze-drying mouse sperm reproduction ability and preservation potential. Reproduction 133:841-846.

Kusakabe H, Szczygiel MA, Whittingham DG, Yanagimachi R. 2001. Maintenance of genetic integrity in frozen and freeze-dried mouse spermatozoa. Proc Natl Acad Sci USA 98:13501-13506.

Liu JL, Kusakabe H, Chang CC, Suzuki H, Schmidt DW, Julian M, Pfeffer R, Bormann CL, Tian XC, Yanagimachi R, Yang X. 2004. Freeze-dried sperm fertilization leads to full-term development in rabbits. Biol Reprod 70:1776-1781.

Oh SH, Miyoshi K, Funahashi H. 1998. Rat oocytes fertilized in modified rat 1-cell embryo culture medium containing a high sodium chloride concentration and bovine serum albumin maintain developmental ability to the blastocyst stage. Biol Reprod 59:884-889.

Saunders CM, Larman MG, Parrington J, Cox LJ, Royse J, Blayney LM, Swann K, Lai FA. 2002. PLC $\zeta$ : A sperm-specific trigger of $\mathrm{Ca}^{2+}$ oscillations in eggs and embryo development. Development 129:3533-3544.

Schatten H, Schatten G, Mazia D, Balczon R, Simerly C. 1986. Behavior of centrosomes during fertilization and cell division in mouse oocytes and in sea urchin eggs. Proc Natl Acad Sci USA 83:105-109.

Szczygiel MA, Kusakabe H, Yanagimachi R, Whittingham DG. 2002. Intracytoplasmic sperm injection is more efficient than in vitro fertilization for generating mouse embryos from cryopreserved spermatozoa. Biol Reprod 67:1278-1284.

Tateno H, Kimura Y, Yanagimachi R. 2000. Sonication per se is not as deleterious to sperm chromosomes as previously inferred. Biol Reprod 63:341-346.

Wakayama T, Yanagimachi R. 1998. Development of normal mice from oocytes injected with freeze-dried spermatozoa. Nat Biotechnol 16:639-641.

Ward MA, Kaneko T, Kusakabe H, Biggers JD, Whittingham DG, Yanagimachi R. 2003. Long-term preservation of mouse spermatozoa after freeze-drying and freezing without cryoprotection. Biol Reprod 69:2100-2108.

Woolley DM, Fawcett DW. 1973. The degeneration and disappearance of the centrioles during the development of the rat spermatozoon. Anat Rec 177:289-302. 